\title{
Heat capacity of biphenyl around its phase transitions at low temperature
}

\author{
A. Dworkin \\ Laboratoire de Chimie Physique des Matériaux Amorphes $\left({ }^{*}\right)$, Bât. 490, Université de Paris-Sud, Centre d'Orsay, \\ 91405 Orsay Cedex, France \\ and H. Cailleau
}

Département de Physique Cristalline et Chimie Structurale (**), Université de Rennes, Campus de Beaulieu, 35042 Rennes Cedex, France

(Res'u le 9 novembre 1979, accepté le 20 décembre 1979)

\begin{abstract}
Résumé. - La chaleur spécifique du biphényl a été mesurée entre 10 et $50 \mathrm{~K}$. On n'a pas observé d'anomalies de chaleur spécifique vers 15 et $40 \mathrm{~K}$, températures auxquelles des transitions de phase sont connues, mais les résultats ne sont pas incompatibles avec l'existence d'une enthalpie de transition inférieure à $10 \mathrm{~J} . \mathrm{K}^{-1} \cdot \mathrm{mol}^{-1}$ à $40 \mathrm{~K}$. A cette température les temps d'équilibre thermique changent brutalement.
\end{abstract}

\begin{abstract}
The heat capacity of biphenyl has been measured between 10 and $50 \mathrm{~K}$. Although no specific heat anomalies could be seen at 15 or $40 \mathrm{~K}$, where phase transitions are known to exist, the results are not inconsistent with a transition enthalpy smaller than $10 \mathrm{~J} \cdot \mathrm{K}^{-1} \cdot \mathrm{mol}^{-1}$ at $40 \mathrm{~K}$. At this temperature, the thermal equilibrium times changed abruptly.
\end{abstract}

1. Introduction. - The angle between the planes of phenyl rings in polyphenyls is not constant with physical state and temperature. In the gaseous state the ortho hydrogen repulsion induces a non planar configuration of the molecule. In the crystal, intermolecular forces, which would tend to give a planar configuration, are of the same order of magnitude as those of some intramolecular ones (interphenyl field); therefore, at room temperature, molecules appear planar like (with a large thermal motion for the torsional angle) but the situation may change as the temperature is lowered.

The first evidence for a phase transition in crystalline biphenyl between 4.2 and $300 \mathrm{~K}$, was given by Hochstrasser et al. [1] in a study of the fluorescence spectrum of biphenyl $h_{10}$ in biphenyl $d_{10}$. Afterwards, Friedman et al. [2] reported a continuous change in the Raman spectrum of powdered biphenyl between 75 and $15 \mathrm{~K}$. Then, Cullick and Gerkin [3] found in E.P.R. experiments, that the transition occurred at $42.3 \mathrm{~K}$, and later on they discovered another transition at $15 \mathrm{~K}$ [4]. Soon after both works were confirmed

(*) Partie du L.A. 75 au C.N.R.S. $\mathrm{n}^{\circ} 75$.

$\left({ }^{* *}\right)$ E.R.A. au C.N.R.S. n" 015 . by Bree and Edelson [5, 6] during optical and Raman studies of single crystals : the transition at $40 \mathrm{~K}$ is continuous and a Raman soft mode is claimed to vanish at this temperature, whereas the $15 \mathrm{~K}$ transition is sudden. Finally Cailleau et al. [7], using neutron diffraction, confirmed that the upper transition was a displacive one and that the lower transition was discontinuous [8] they also showed that the two low temperature structures were incommensurate.

Friedman had announced in his paper [2] that a thermodynamic study was in progress, but it was never published. On the other hand, Cullick and Gerkin [3] reported a thermal behaviour of biphenyl rather hard to understand : they observed a halt during a continuous cooling of their sample, but nothing during its heating. They gave nevertheless an estimate of $300 \mathrm{~J} . \mathrm{mol}^{-1}$ for the transition enthalpy. It was therefore of interest to undertake a study of the heat capacity of biphenyl at low temperature.

2. Experimental. - A sample of $66.7231 \mathrm{~g}$ of biphenyl purified by zone melting was introduced into the calorimeter and sealed under a slight helium pressure.

The adiabatic, submarine type, calorimeter used in this study has been fully described elsewhere [9]. 
Temperatures are measured with a calibrated $\mathrm{Pt}$ resistance thermometer (Leeds and Northrup) by a potentiometric method with a Tinsley potentiometer (4363 D auto) also used for the energy measurements. The temperature of the adiabatic shield is kept automatically equal to that of the calorimeter within $0.3 \mathrm{~K}$. The overall accuracy of the results obtained is estimated to be usually $\pm 0.3 \%$.

3. Results. - A cooling curve and two heating curves are shown in figure 1 for temperatures in the neighbourhood of $40 \mathrm{~K}$ : no thermal anomaly can be seen. If the derivative quantity $\Delta T / \Delta t$ is plotted against $T$ (Fig. 2) some scatter appears, but the anomalies are not reproducible and never exceed the experimental error.

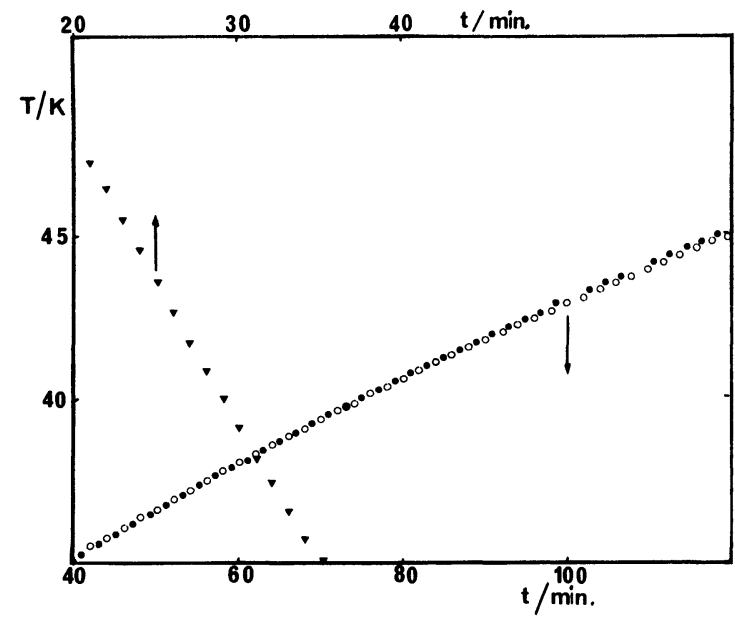

Fig. 1. - Cooling $(\nabla)$ and heating $(0,0)$ curves of biphenyl as a function of time.

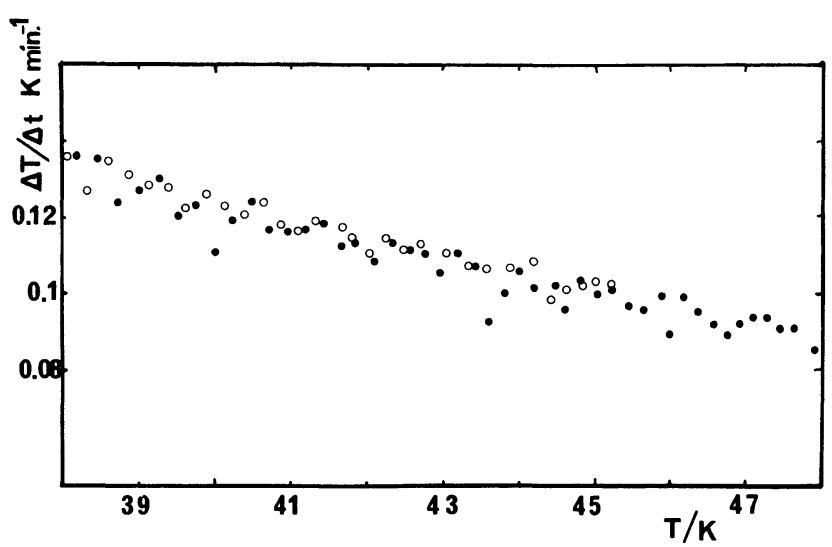

Fig. 2. - Heating speed as a function of temperature.

The heat capacity curve given in figure 3 is monotonic, but during the experiments it was noted that the equilibrium times necessary to obtain a constant temperature drift became progressively longer than usual (to reach $80 \mathrm{~min}$.) until the temperature was greater than $40 \mathrm{~K}$, where they happened to be normal again $(20 \mathrm{~min}$.). During this period these temperature drifts - used to calculate the corrections required

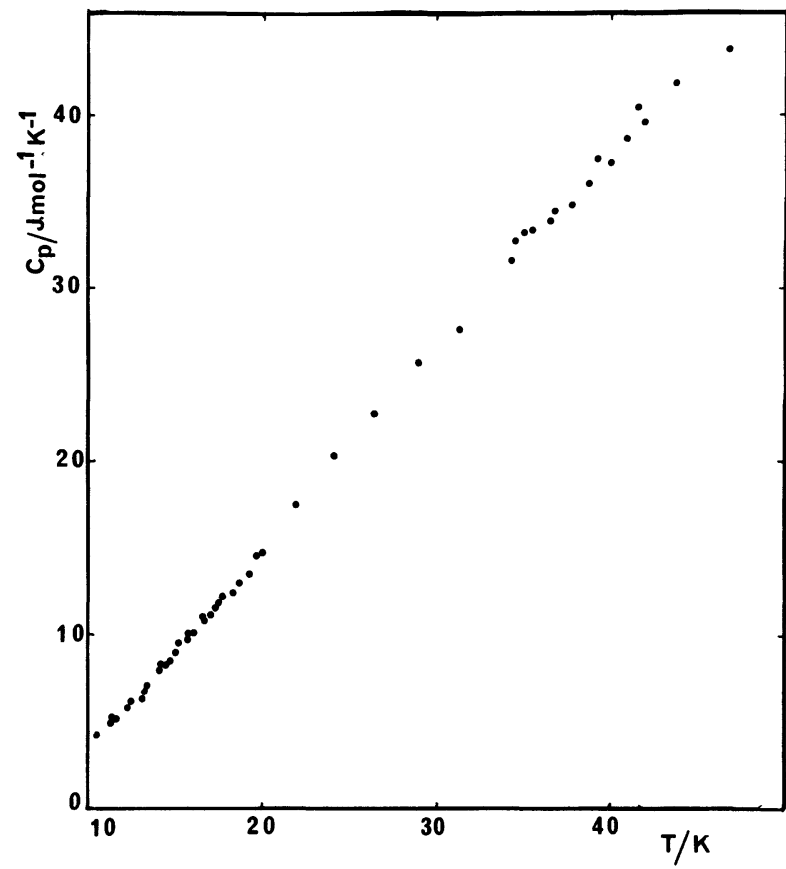

Fig. 3. - Specific heat of biphenyl as a function of temperature.

to determine the temperature at the middle of the heating period - were, quite irregular. Therefore a study at smaller temperature intervals would have been useless, the corrections being too large with respect to the interval itself.

The heat capacities in the low temperature region did not show an anomaly either. In that case no difficulties were encountered in the experiments.

The difference in equilibrium times would have been hardly noticed in previous studies which dealt with small samples always in equilibrium with a thermal bath [1-8].

4. Discussion. - At temperatures higher than $90 \mathrm{~K}$, the results obtained in these experiments were in good agreement with the values previously published by Huffman et al. [10].

The temperature intervals used in the $40 \mathrm{~K}$ region are rather large : $\pm 2 \mathrm{~K}$. It may be thought therefore that a thermal anomaly could have escaped detection in these measurements. Using comparable amounts of material and the same apparatus, some phase transitions have been detected in the past even with large temperature intervals : with 0.2 mole of p-terphenyl a measurement between 191.55 and $193.93 \mathrm{~K}$ showed a characteristic $4 \%$ increase of $C_{p}$ due to a transition enthalpy of $96.5 \mathrm{~J} . \mathrm{mol}^{-1}[11]$ or of $135 \mathrm{~J} \mathrm{.} \mathrm{mol}{ }^{-1}$ if a slightly different base line is used [12]; the transition of a 0.33 mole sample of benzil was detected by a peak of $C_{p}$ between 83.01 and $85.55 \mathrm{~K}$ larger by $10 \%$ than the neighbouring values, and the associated $\Delta H$ was only $44 \mathrm{~J}^{-\mathrm{mol}^{-1}}$ [13].

Consequently an upper limit to the transition enthalpy may be given as around $10 \mathrm{~J} \cdot \mathrm{mol}^{-1}$. This value represents the product of the experimental 
error on the heat capacities between 35 and $45 \mathrm{~K}$ by this temperature interval. Other studies using specially designed calorimeters with a very good temperature resolution $[12,14]$ would be necessary to clarify this point.

Such small values for transition enthalpies are by no means exceptional. In chloranil $\Delta H=38 \mathrm{~J} . \mathrm{mol}^{-1}$ [15], in thiourea $\Delta H$ are equal to 7 and $28 \mathrm{~J} \cdot \mathrm{mol}^{-1}$ respectively for the two lower temperature transitions [16], whereas in $\mathbf{N}, \mathbf{N}^{\prime}$-dimethylnitramine $\Delta H=18 \mathrm{~J} . \mathrm{mol}^{-1}[17]$. Even smaller values may be found in Rochelle salt [18].
The fact that in biphenyl $\Delta H$ is rather small whereas it is noticeable in p-terphenyl, appears as a confirmation of the different nature of the phase transitions in these two compounds : order-disorder for the latter and displacive for the former, as were also those occurring in chloranil, thiourea and $\mathrm{N}, \mathrm{N}^{\prime}$ dimethylnitramine.

Finally it must be noted that only a very small transition enthalpy is expected at the low temperature transition between two incommensurate phases, even if this event occurs suddenly : in $\mathrm{K}_{2} \mathrm{SeO}_{4}$ [19] such a situation was hardly noticeable.

\section{References}

[1] Hochstrasser, R. M., McAlpine, R. D. and Whiteman, J. D., J. Chem. Phys. 58 (1973) 5078.

[2] Friedman, P. S., Kopelman, R. and Prasad, P. N., Chem. Phys. Lett. 24 (1974) 15

[3] Cullick, A. S. and Gerkin, R. E., Chem. Phys. Lett. 42 (1976) 589.

[4] Cullick, A. S. and Gerkin, R. E., Chem. Phys. 23 (1977) 217

[5] Bree, A. and Edelson, M., Chem. Phys. Lett. 46 (1977) 500.

[6] Bree, A. and Edelson, M., Chem. Phys. Lett. 55 (1978) 319.

[7] Callleau, H., Girard, A., Moussa, F. and Zeyen, C. M. E., Solid State Commun. 29 (1979) 259.

[8] Cailleau, H., Moussa, F. and Mons, J., Solid State Commun. 31 (1979) 521.

[9] Lagarrigue, M., Thèse Orsay 1973, A.O. CNRS No 9804.

[10] Huffman, H. M., Parks, G. S. and Daniels, A. C., J. Am. Chem. Soc. 52 (1930) 1547.

[11] Callleau, H. and Dworkin, A., Mol. Cryst. Liq. Cryst. 50 (1979) 217.
[12] Chang, S. S., Proc. 7th Symp. Thermophysical properties. Am. Soc. Mech. Eng., N.B.S. 1977, p. 75 and private communication.

[13] Dworkin, A. and Fuchs, A. H., J. Chem. Phys. 67 (1977) 1789.

[14] Tatsumi, M., Matsuo, T., Suga, H. and Seki, S., Bull. Chem. Soc. Japan 48 (1975) 3060

[15] Chimara, H. and Matsukane, K., J. Chem. Phys. 59 (1973) 5397.

[16] Chang, E. and Westrum, E. F. Jr., Phys. Chem. Org. Solid State, I, D. Fox, M. M. Labes and A. Weissberger Eds. (Interscience New York) 1963, p. 127.

[17] Rey-Lafon, M. and Lagnier, R., Mol. Cryst. Liq. Cryst. 32 (1976) 13.

[18] Tatsumi, M., Matsuo, T., Suga, H. and Seki, S., J. Phys. Chem. Solids 39 (1978) 427.

[19] Aiki, K., Hukuda, K., Koga, H. and Tobayashi, T., $J$. Phys. Soc. Japan 28 (1970) 389. 